Revista Destaques Acadêmicos, Lajeado, v. 11, n. 1, 2019. ISSN 2176-3070

DOI: http://dx.doi.org/10.22410/issn.2176-3070.v11i1a2019.1799

http://www.univates.br/revistas

\title{
ANÁLISE DA LOGÍSTICA INTERNA NO CENTRO DE DISTRIBUIÇÃO DA REDE DE LOJAS BENOIT DE LAJEADO/RS
}

\author{
Lucimara Vieira Neves, Hélio Diedrich
}

\begin{abstract}
Resumo: Este artigo trata da análise e proposição de melhorias dos processos da área de logística interna do Centro de Distribuição da rede de Lojas Benoit, situado na cidade de Lajeado-RS. O estudo tem por objetivo principal sugerir ações de melhoria que possam ser adotadas, a fim de aperfeiçoar as operações de logística da empresa. O objetivo secundário da pesquisa é identificar os processos praticados, apontar o caminho mais eficiente para uma melhor movimentação e armazenagem e indicar possíveis problemas nas operações de logística interna. Para a geração dos dados é utilizado o questionário com base no livro "Check sua Logística Interna", elaborado por Reinaldo A. Moura (1998). As atividades avaliadas dentro do processo logístico interno do Centro de Distribuição foram as seguintes: logística, recebimento, estocagem, movimentação e a estocagem em processo, embalagem, armazenagem e expedição. O questionário é aplicado com informações dos gestores e operários que atuam dentro dos processos logísticos da empresa. As observações são feitas in loco, buscando uma melhor visão de todo o processo, coletando informações e detalhes. O estudo é de cunho qualitativo quantitativo e se dá através de uma pesquisa exploratória.
\end{abstract}

Palavras-chave: Logística Interna. Análise e Melhoria de Processos. Logística.

\section{INTRODUÇÃO}

A logística interna engloba todos os fluxos e movimentações físicas e operações de apoio nos processos realizados dentro do depósito, tais como: recepção de produtos, armazenagem, expedição, abastecimento de linhas de produção, paletização e etiquetagem.

A grande competitividade e a constante busca por reduzir o tempo e os custos operacionais, leva os gestores a procura da melhoria contínua e da otimização dos processos logísticos internos, eliminando as atividades que não acrescentam valor agregado ao produto.

A busca por melhoria na logística interna da empresa, não é simples, por isso a importância de se estudar detalhadamente cada processo com a possibilidade de visualizar novas formas de realizar as tarefas de um modo 
mais eficaz, diminuindo as falhas, o retrabalho e principalmente o custo, pois esse está diretamente ligado aos resultados financeiros das organizações.

Este artigo objetiva, a partir da análise e proposição de melhorias, aperfeiçoar o desempenho da logística interna e sugerir ações que possam contribuir com os processos de: armazenagem, recebimento, estocagem, movimentação, embalagem e expedição da Rede de Lojas Benoit. E, de forma complementar, define-se como específicos, os objetivos a seguir ordenados: (1) identificar os processos logísticos internos praticados (2) apontar possíveis problemas visando o melhor desempenho das operações de logística interna (3) apresentar a Direção da empresa ideias que provavelmente irão proporcionar redução de custos e o aumento do nível de serviço oferecido aos clientes (4) através de um gráfico mostrar os resultados alcançados.

A demanda de produtos que giram dentro do Centro de Distribuição da Rede de lojas Benoit é significativa, onde a todo o momento é possível acontecer falhas, entre elas: recebimento de produto com avaria, embalagem molhada ou rasgada, armazenamento e movimentação inadequados, separação de pedidos feitos incorretamente e pedidos misturados, ocorrendo erros internos que atrapalham o fluxo normal do Centro de Distribuição.

A empresa analisada, Benoit Eletrodomésticos Ltda., é uma rede varejista com atuação no Rio Grande do Sul, Santa Catarina e Paraná, tem 46 anos desde sua fundação, possui mais de 230 lojas e conta com aproximadamente 2700 colaboradores. A pesquisa é realizada no Centro de Distribuição da Rede de Lojas Benoit, na cidade de Lajeado-RS.

\section{FUNDAMENTAÇÃO TEÓRICA}

No desenvolvimento da fundamentação teórica são abordados conceitos e opiniões de autores objetivando dar sustentação aos assuntos tratados ao longo do estudo.

\subsection{Armazenagem}

A armazenagem surge da falta de informações qualificadas de demandas futuras, portanto, quanto menor o controle da demanda maior a necessidade de armazenagem, o ideal seria nenhum armazenamento, mas para uma empresa varejista que precisa abastecer suas lojas todos os dias e ter o produto em estoque para vendê-lo, não se trabalha com estoque zero.

Conceitualmente o armazém existe para proporcionar um "estoquepulmão", no local onde for necessário. Mas, se estocar não agrega valor ao produto, por que estocamos? Estocamos porque, embora seja notório o progresso nas técnicas de redução de inventários, a armazenagem ainda se mostra necessária nos casos em que, para atender as suas demandas logísticas, as empresas precisam de 
estoques a médio ou a longo prazo. Assim esse processo ocorre, entre outras razões, para melhorar o atendimento aos consumidores, reduzir custos de frete e otimizar custos de produção (RUSSO, 2009, p. 17).

Além dos conceitos do autor a armazenagem busca alcançar objetivos com a maximização do uso do espaço pelo volume do produto, aproveitamento eficaz dos recursos humanos e dos equipamentos uma vez que são utilizados em atividades que não agregam valor ao produto, facilidade de acesso aos itens estocados com um layout bem planejado, qualidade na armazenagem com um bom planejamento, proteção total dos itens evitando a perda ou dano, eficiência na movimentação onde não agrega valor ao produto mas agrega custos e é a maior atividade na estocagem.

\subsection{Logística interna}

A logística interna engloba todos os fluxos e movimentações físicas e operações de apoio que são realizadas dentro de um armazém. Várias tarefas são executadas, como por exemplo: recepção de produto, armazenagem, expedição, embalagem, paletização e etiquetagem.

Sousa (2002, p. 30) afirma em seu estudo que "a logística interna refere-se a todo o processo de recebimento, guarda, controle e distribuição dos materiais utilizados dentro de uma organização. Nas indústrias a logística interna é um fator primordial para a obtenção de eficiência e do aumento nas quantidades produzidas".

Para Moura (1998) nos anos de 1990 a competitividade obrigou as empresas a procurarem novos mercados e a derrubarem as barreiras internacionais, onde os blocos de livre comércio ganharam força. A partir disso o fator tempo foi determinante para o sucesso das organizações, acabou-se o tempo que o grande engolia o pequeno, hoje o mais rápido engole o mais lento. A empresa que mais rapidamente percebe a necessidade do cliente, que lança um produto novo, que entrega num prazo mais curto possui grande chance de sobreviver e prosperar.

\subsection{Análise e melhoria de processos}

A análise e melhoria dos processos poderia ser uma atividade rotineira nas organizações, pois somente assim poderão se adaptar as mudanças que ocorrem constantemente no mundo globalizado. A gestão desse processo é importante para qualquer tipo de empresa, já que a necessidade de coordenar acontece da própria ação de dividir e organizar o trabalho em um todo.

Para realizar as tarefas de um modo eficaz, diminuindo as falhas, o retrabalho e o custo, cada etapa da análise e melhoria dos processos serão verificadas cuidadosamente. Essas melhorias têm como objetivo aumentar 
a satisfação dos clientes, reduzir perdas, e aumentar o lucro (KRAJEWSKI; RITZMAN; MALHOTRA, 2009).

Melhoria de processos é o estudo sistemático das atividades e fluxos de cada processo para melhorá-lo. Sua finalidade é "saber os números", entender o processo e extrair os detalhes. Uma vez que um processo é entendido, ele pode ser melhorado. A pressão incansável para proporcionar melhor qualidade a preços mais baixos, significa que as empresas devem rever continuamente todos os aspectos de suas operações (KRAJEWSKI; RITZMAN; MALHOTRA, 2009, p. 119, grifo do autor).

Taylor (1992) começou a estudar o problema da melhor alocação dos recursos para otimizar a produtividade da empresa, mas seu estudo foi limitado ao homem ou a máquina, onde a melhoria deveria voltar-se ao processo, mais especificamente, para o fluxo de produtos, ficando estabelecido a diferença entre os fins (fluxos de produtos) e que estariam relacionados com as melhorias dos processos e os meios (recursos) que estariam relacionados com a melhoria das tarefas.

\subsection{Gerenciamento da cadeia de suprimentos - Supply Chain Management}

O gerenciamento da cadeia de suprimentos busca auxiliar na redução dos custos ao longo do processo, portanto, é necessário que todos os setores da empresa estejam interligados para que monitorem desde a aquisição do produto, produção do item, armazenamento, entrega e o feedback do cliente.

No fluxo normal de uma cadeia de suprimentos as matérias-primas são compradas, os produtos são produzidos em uma fábrica, ou mais de uma, e são transportados para um centro de distribuição ou depósito, onde serão armazenados e posteriormente encaminhados aos varejistas ou clientes. A cadeia de suprimentos também é chamada de rede logística onde estão incluídos fornecedores, depósitos, centros de distribuição, varejistas, centros de produção, matérias-primas, estoque de produtos acabados e em processo (LEVI; KAMINSKY; LEVI, 2010).

Ballou (2006) afirma que o produto é o centro no foco de uma cadeia de suprimentos, pois ele é o gerador de receitas da empresa, um bom projeto de sistema logístico depende do entendimento deste elemento básico, sendo a razão para que dimensões do projeto, como embalagem e preço, sejam exploradas como um elemento do serviço ao cliente.

Dentro de cada organização a cadeia de suprimentos inclui todas as funções para atender a demanda solicitada, entre elas estão o desenvolvimento de novos produtos, marketing, operações, distribuição, finanças e o serviço de atendimento ao cliente (CHOPRA; MEINDL, 2003, p. 3). 


\subsection{Expedição}

A expedição é o departamento da empresa responsável pelas mercadorias enviadas às lojas, onde é feito o planejamento do transporte dos itens solicitados, verificado o estado das embalagens, carregamento dos veículos, conferência e acompanhamento até a chegada na loja.

Para Moura (1997) o ideal é que um empregado retire a mercadoria do local de armazenamento e outro faça a conferência e o carregamento, facilitando o controle e a incidência de erros. $\mathrm{O}$ autor entende que a doca de expedição é um bom lugar para a descoberta de erros cometidos pelos separadores de pedidos. Ao contrário Banzato e Fonseca (2008) afirmam que as atividades devem ser simplificadas pois elas acrescentam custos ao processo de expedição, onde podem afetar o espaço interno e o externo do armazém, analisando as seguintes necessidades: área de pedidos prontos para carregar; área de conferência de pedidos e consolidação de carga; área de circulação de equipamentos e movimentação de cargas; área de carregamentos dos veículos; área de estacionamento dos veículos; área para circulação e áreas para controle de acesso. Ainda para os autores no processo de armazenagem a expedição é a última atividade a ser realizada e um projeto adequado do processo de expedição é uma das condições básicas para um serviço de boa qualidade ao cliente.

\subsection{Movimentação de materiais}

Dentro do Centro de Distribuição a movimentação de materiais não é somente levar o produto de um ponto ao outro, tem que ter um planejamento de tarefas, turnos de colaboradores e horários de pico, para que o trabalho possa fluir normalmente sem engarrafamentos nos corredores ou possíveis acidentes.

Moura (2005) informa que a movimentação de materiais é qualquer movimento até o produto acabado, podendo ser em uma unidade industrial, armazém ou terminal de carga, desde a recepção, embalagem e estocagem até a expedição.

Conforme Rezende (2005, p. 206) “as empresas costumam fazer mudanças nas movimentações de materiais sem antes analisar e avaliar as consequências, muitas vezes aprendem com experiências ruins", um exemplo é a troca de uma entrega semanal para uma entrega de mercadoria diária, onde essa mudança pode exigir cinco vezes mais movimentações.

Para Moura (2005, p. 5) "Estima-se que a movimentação de materiais representa entre $15 \%$ a $20 \%$ do custo total de um produto fabricado. Certamente, ela é um dos primeiros lugares onde procurar por reduções no custo". 


\section{PROCEDIMENTOS METODOLÓGICOS}

Essa etapa do artigo tem o objetivo de mostrar os tipos de procedimentos mais utilizados na pesquisa, os métodos são: o qualitativo e o quantitativo. A pesquisa é aplicada pois seu estudo será baseado na empresa citada.

Quando o objeto enfoca o conhecimento de forma concreta, objetiva, mensurável e com dados estatísticos, o método indicado é o quantitativo. Quando o objeto é traduzido em seu subjetivismo, isto é, relativo a um fenômeno não mensurável, o método é o qualitativo, e quando o objeto admite a integração dos dois, o método mais adequado é o quali-quantitativo (FIGUEIREDO; SOUZA, 2011).

A pesquisa qualitativa não busca a generalização, quando da análise dos dados coletados, ela terá por objetivo apenas "compreender um fenômeno em seu sentido mais intenso, produzindo inferências que possam levar à constituição de leis gerais ou a extrapolações que permitam previsões válidas sobre a realidade futura" (APPOLINÁRIO, 2006, p. 159).

Para Malhotra (2006), a pesquisa quantitativa tem o objetivo de quantificar os dados e generalizar os resultados da amostra para a populaçãoalvo; normalmente é usada para amostras com grande número de casos; a coleta de dados é estruturada; a análise de dados é estatística e os resultados recomendam uma linha de ação final.

A pesquisa é caracterizada como exploratória, pois de acordo com Beuren (2006), explorar um assunto pode reunir mais conhecimento, incorporar características desconhecidas e buscar novos procedimentos.

Nos procedimentos técnicos temos a pesquisa como documental, onde foram analisados os documentos com o histórico da empresa, onde eles já são estruturados e servem de base a pesquisadora. Na pesquisa de campo temos um estudo com maior profundidade, desenvolvida em cenários naturais, feita in loco com observação direta. Na pesquisa de observação é um instrumento de coleta de dados para investigar a realidade da empresa, vendo, ouvindo e examinando fatos. A entrevista não-estruturada focalizada foi realizada com o Coordenador do Centro de Distribuição, onde foram formuladas perguntas sem obedecer uma estrutura formal. O questionário foi elaborado com perguntas claras, informações sobre o correto preenchimento das questões e com linguagem acessível ao entendimento dos funcionários do Centro de Distribuição.

\section{APRESENTAÇÃO E ANÁLISE DOS RESULTADOS}

$\mathrm{O}$ estudo teve como base o check list sugerido pelo autor Reinaldo A. Moura, do livro "Check sua Logística Interna". O questionário foi aplicado no Centro de Distribuição com dez funcionários escolhidos aleatoriamente pela pesquisadora, permitindo assim ter uma análise mais detalhada de todos os 
processos através das informações coletadas. O questionário foi composto por sete etapas: Logística; Recebimento; Estocagem; Estocagem em Processo; Embalagem; Armazenagem e Expedição.

Cada etapa foi formada por 15 questões, onde foi solicitado aos entrevistados responderem "Sim", "Em Parte" e Não. Como a empresa não fabrica os produtos, em algumas questões da etapa Embalagem foi necessário utilizar por diversas vezes a opção "Em Parte" e "Não". No gráfico 1 os percentuais informados representam a quantidade de cada item em relação ao total apurado.

$\mathrm{Na}$ análise in loco também foi feita uma entrevista com o Coordenador de Logística do CD, com a finalidade de buscar mais dados e informações relevantes para o aprimoramento e qualificação dos processos da Logística Interna do Centro de Distribuição.

O processo de armazenagem e movimentação engloba várias etapas, desde a compra do produto, recebimento, conferência de caminhão, controle de estoque, armazenagem e o fluxo inverso onde acontece o carregamento dos produtos estocados para serem distribuídos nas lojas da rede.

A compra do produto acontece na Matriz da empresa pelo Departamento Comercial, onde os representantes das mais variadas marcas de eletrodomésticos, brinquedos, celulares, som e imagem, móveis e bazar apresentam seus catálogos. Após análise e necessidade de compra é efetuado o pedido com as quantidades desejadas, mediante consulta do estoque e de acordo com a demanda, sazonalidade e produtos novos no mercado.

Após a compra do produto é feito o agendamento da carga para a entrega no Centro de Distribuição, hoje em dia o agendamento e feito de forma manual onde os dados são preenchidos em uma planilha do excel.

Com o agendamento da entrega em mãos, as transportadoras e os caminhões das marcas se dirigem até o Centro de Distribuição para a entrega das mercadorias, onde entregam a nota fiscal na portaria e aguardam o horário da descarga. Para a descarga é cobrado um valor predefinido, dependendo da quantidade de produtos e o tipo da carga.

Com a nota fiscal correta e o valor da descarga acertado, a transportadora ou o caminhão da marca pode entrar no box para descarga, onde o produto é conferido e etiquetado item por item. Com as devidas etiquetas coladas nos produtos, já podem ser alocadas nos paletes, que posteriormente serão destinados aos setores que pertencem. Essa movimentação é feita através das paleteiras manuais, elétricas e empilhadeiras. O CD conta com 25 paleteiras elétricas, 15 manuais e 6 empilhadeiras.

Para o carregamento, o processo é o inverso, onde ocorre da seguinte forma, na primeira hora da manhã o líder de equipe gera um relatório com as importações feitas na noite anterior, contando todos os produtos solicitados pelas filiais e os produtos que foram vendidos e automaticamente serão repostos 
nessa carga. Os conferentes e auxiliares fazem a separação dos produtos, eles vão sendo encaminhados para o box de carregamento. A primeira conferência é manual e a segunda é feita através do coletor. Dentro do caminhão os produtos são carregados em forma de fileira, os itens mais pesados como estofados e móveis fazem uma parede para firmar a carga, os itens mais leves são carregados posteriormente.

Dependendo da quantidade de itens a serem carregados um caminhão pode levar até 8 cargas para 8 filiais diferentes, isso varia muito com a época do ano, a quantidade de produtos que a filial vende, ou, por exemplo, se tem alguma promoção de determinado item elevando a venda do mesmo. Seguindo o roteiro predeterminado, quando o caminhão chega na filial, o Gerente recebe a nota, faz a conferência manual dos itens, testa alguns deles para verificar se não ocorreu nenhuma avaria no percurso e o caminhão está liberado, as mercadorias são armazenadas na loja e estão prontas para serem comercializadas.

Gráfico 1 - Análise da Logística Interna

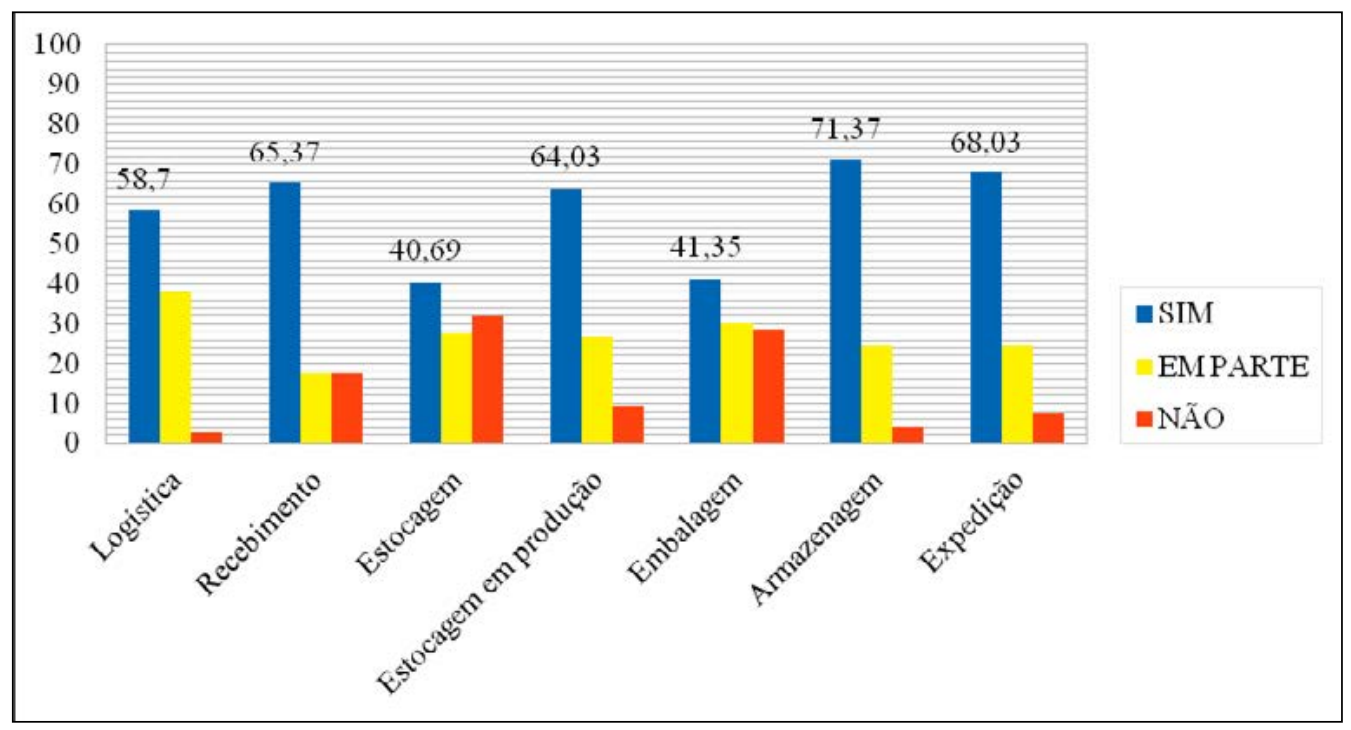

Fonte: elaborado pelos autores.

\subsection{Análise da logística - visão estratégica}

Conforme as respostas obtidas nos questionários a logística de forma geral no Centro de Distribuição está com uma boa pontuação, ainda não chegou no resultado ideal que seria acima de $75 \%$, abaixo o gráfico com os percentuais. 
Gráfico 2 - Análise da Logística (visão estratégica)

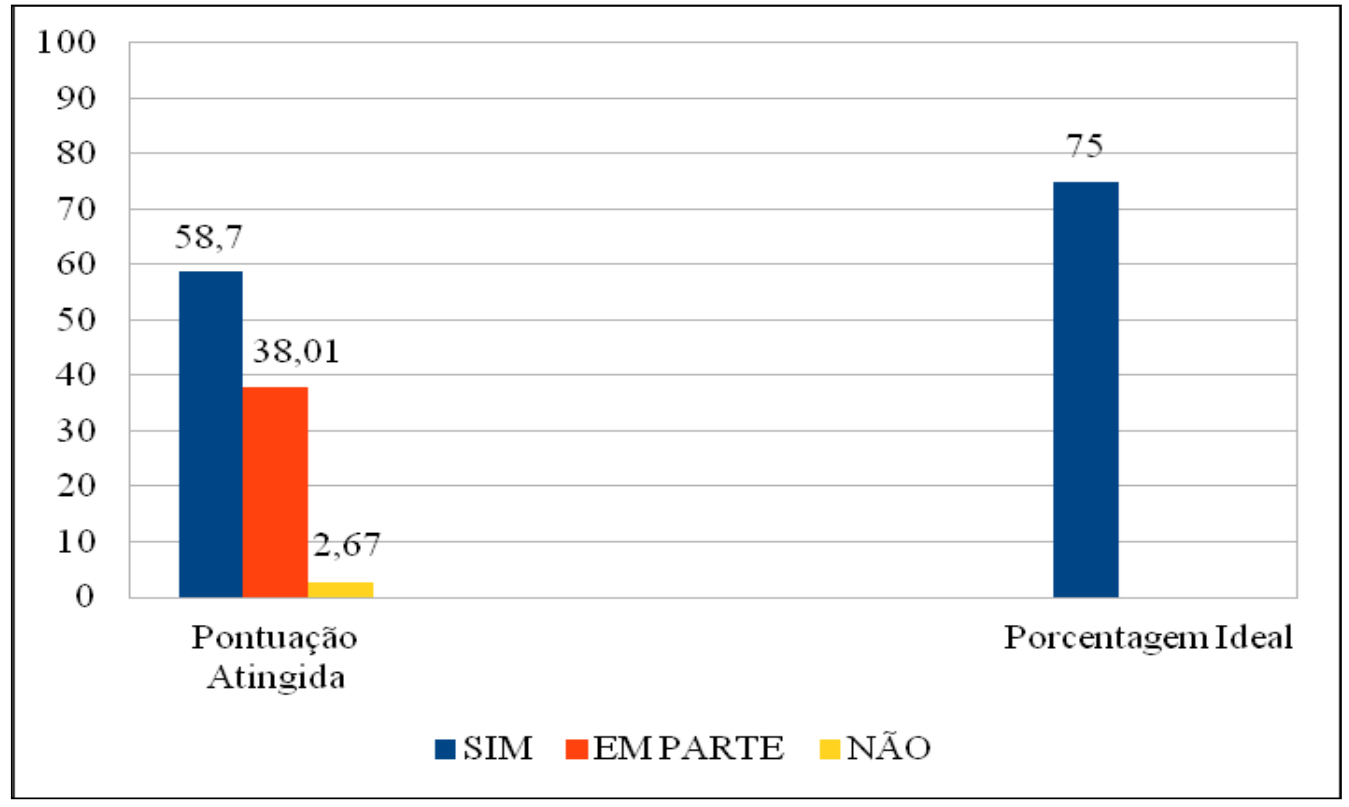

Fonte: elaborado pelos autores.

\subsubsection{Sugestões de melhoria}

O Centro de Distribuição hoje trabalha com o sistema ERP (Enterprise Resource Planning) que é o Planejamento dos Recursos da Empresa, a sugestão para o CD é implantar o sistema WMS (Warehouse Management System) ou Sistema de Gerenciamento de Armazém, que é bem completo comparado ao ERP. No WMS o controle de estoque é por endereço, ocorre a divisão da carga de trabalho, melhor ocupação dos espaços, redução de erros pois o sistema define as tarefas e utilização de código de barras. Uma vantagem desse sistema é que todos os produtos que entrarem nas lojas pode acompanhar a vida útil dele, desde a fabricação, hoje muitos fornecedores deixam de dar assistência para os produtos com data de fabricação superior a 18 meses, evitando que esses produtos fiquem obsoletos nas prateleiras ou estoque das lojas, ou até mesmo no estoque do CD.

No Centro de Distribuição tem um relatório de custo geral, com o sistema WMS implantado ele fornece dados e indicadores por setores, mensurando cada etapa do processo logístico da empresa e facilitando calcular os custos setoriais.

O Centro de Distribuição conta com 160 funcionários, nos turnos da manhã e tarde, e aproximadamente $8 \%$ somente tem formação superior na área de Logística, como sugestão, a empresa poderia oferecer bolsa de estudos com 
parceria com a Universidade Univates, as bolsas poderiam ser de acordo com o tempo de empresa, cargo ou merecimento.

Sugere-se a empresa que faça reuniões mensais e treinamentos para os colaboradores ficarem cada vez mais comprometidos com o trabalho e o resultado seja cada vez mais positivo.

\subsection{Recebimento}

Diante do bom desempenho do recebimento, cabe ressaltar a direção que continue trabalhando de forma eficaz para atingir resultados ainda melhores.

Gráfico 3 - Recebimento

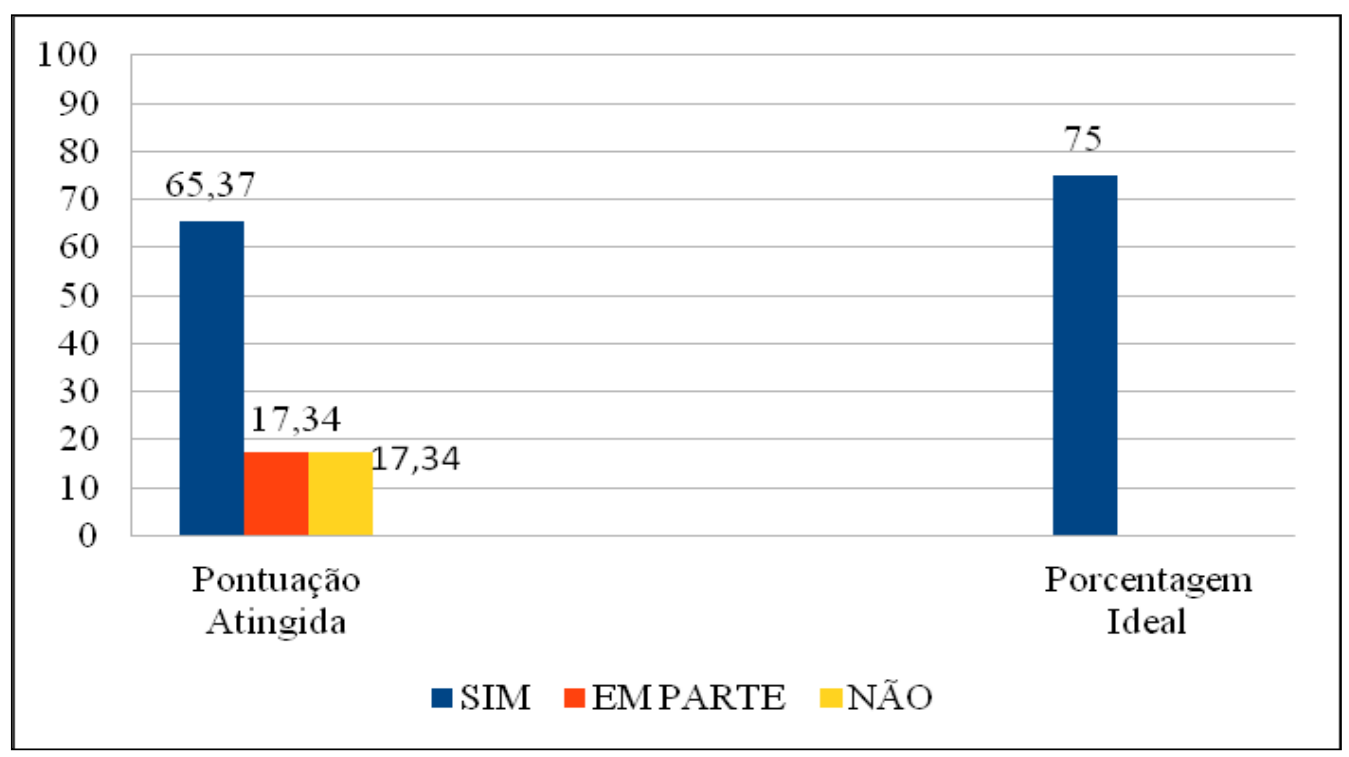

Fonte: elaborado pelos autores.

\subsubsection{Sugestões de melhoria}

Como sugestão de melhoria para o recebimento, o setor de compras e agendamento, poderia criar no site da Benoit, um campo destinado aos fornecedores, onde o próprio fornecedor pode agendar a sua carga, dependendo das datas disponíveis e ficando visível para ambos os setores, facilitando as entregas, ganhando agilidade e tempo.

É necessário também que se estipule um valor fixo das descargas, pois atualmente os valores dependem das quantidades que serão entregues, onde os fornecedores já possam vir com o valor correto evitando perder tempo na hora do pagamento. 


\subsection{Estocagem}

$\mathrm{Na}$ atividade de estocagem temos uma porcentagem bem abaixo do ideal, onde mais de $75 \%$ seria excelente, de $50 \%$ até $75 \%$ seria bom, mas com melhorias a serem feitas e abaixo de $50 \%$ seriam um fator crítico.

Gráfico 4 - Estocagem

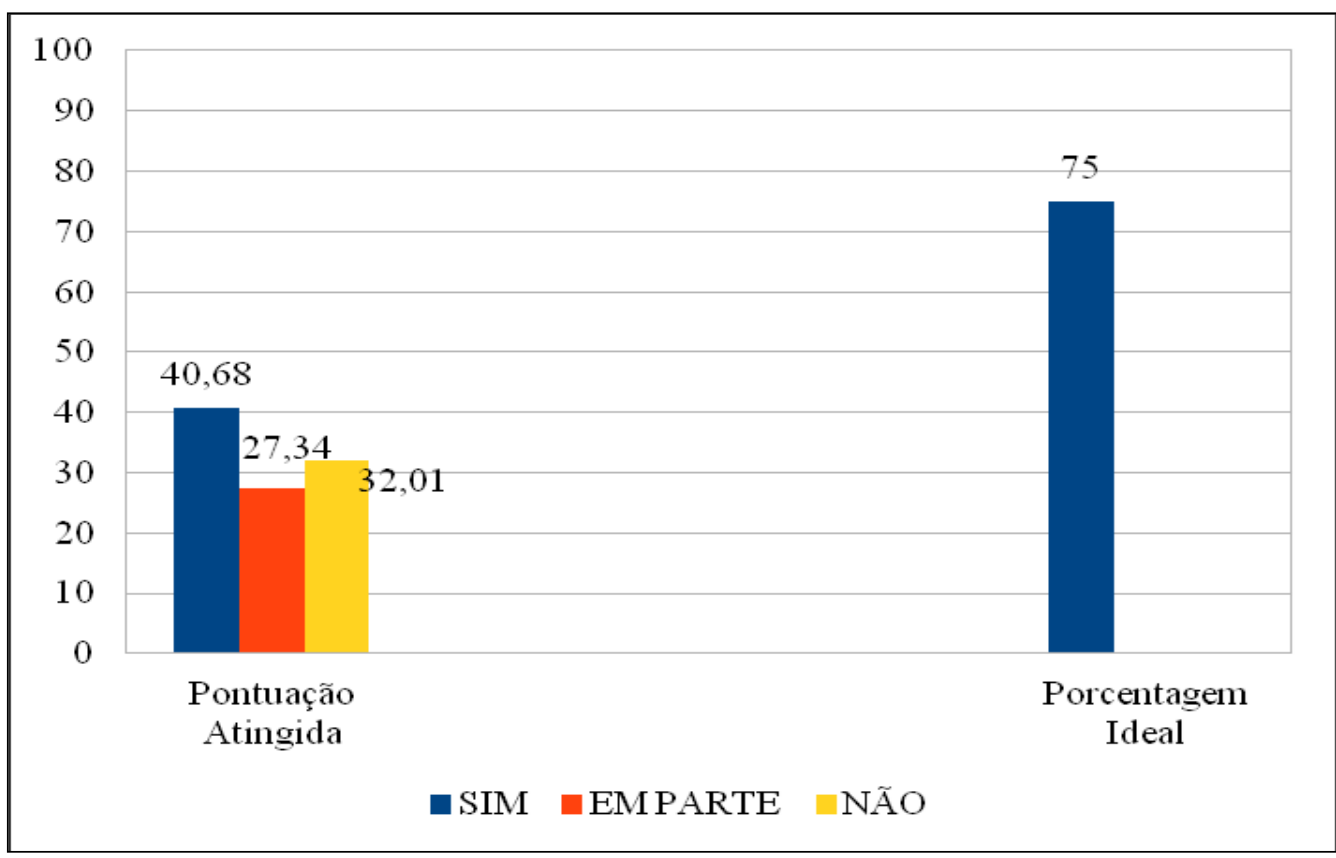

Fonte: elaborado pelos autores.

\subsubsection{Sugestões de melhoria}

Para melhorar o resultado da estocagem, sugere-se que os corredores não tenham produtos estocados, facilitando a passagem das empilhadeiras e paleteiras, reduzindo custos e horas desperdiçadas.

Para que todos os produtos fiquem estocados de forma segura e de rápida visualização e movimentação sugere-se que a capacidade física de estocagem do armazém seja aumentada, ou transferida para um prédio maior, pois hoje não suporta mais o estoque que a empresa possui e necessita para abastecer as lojas. 


\subsection{Movimentação e a estocagem em processo}

Esse item está próximo ao ideal sugerido, conforme gráfico abaixo, mas ainda tem melhorias e mudanças que podem ser realizadas para um melhor desempenho.

Gráfico 5 - Movimentação e a Estocagem em processo

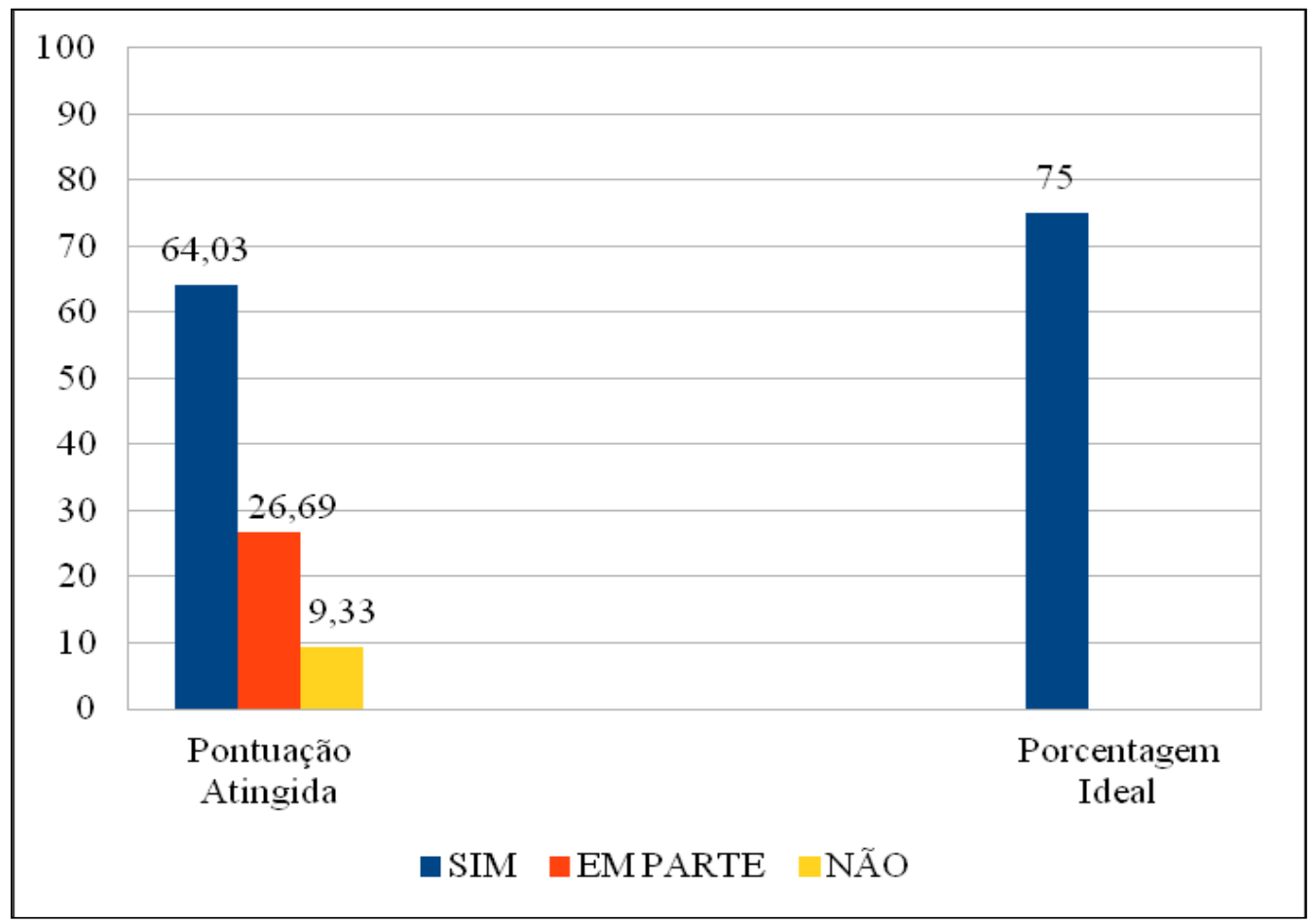

Fonte: elaborado pelos autores.

\subsubsection{Sugestões de melhoria}

Com o fluxo de movimentação de empilhadeiras e paleteiras intenso, sugere-se que as linhas delimitadoras no chão sejam pintadas novamente para facilitarem o percurso das máquinas e para orientar os colaboradores para que não aconteça nenhum acidente, possibilitando também segurança dos visitantes.

No RS temos a região de Porto Alegre que utiliza a voltagem 110v, e no $\mathrm{CD}$ tem um corredor somente com produtos nessa voltagem, mas pouco sinalizado, um funcionário novo poderia não identificar o corredor correto e separar esse produto como sendo 220v e encaminhar para a loja, causando um grande transtorno para o cliente que adquirir o item com a voltagem errada, 
como sugestão para esse setor é a melhor identificação com placas e indicações de voltagem.

\subsection{Embalagem}

Todos os produtos já vêm com a embalagem da sua respectiva fábrica, no Centro de Distribuição somente acontece o manuseio das mesmas na movimentação.

Gráfico 6 - Embalagem

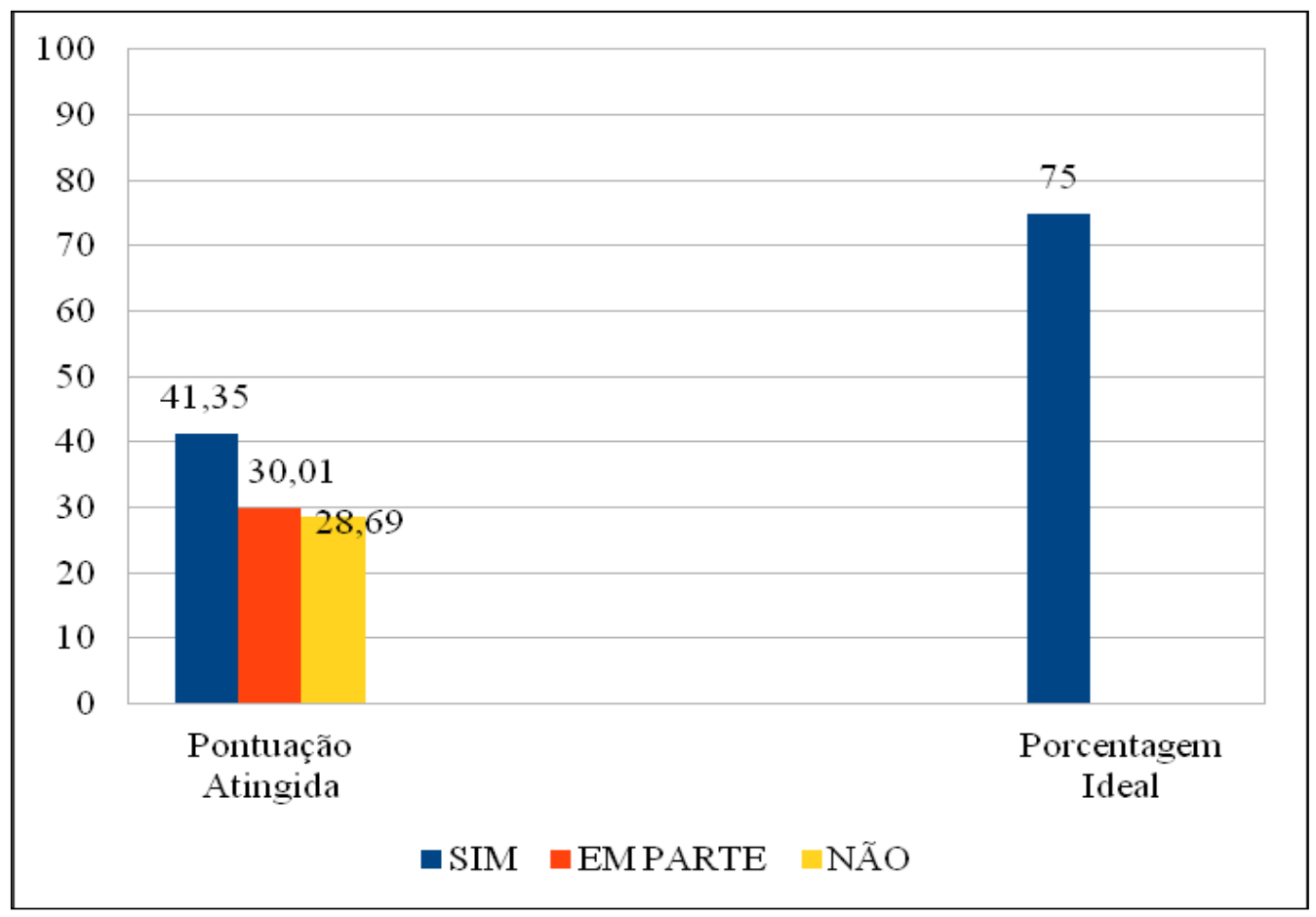

Fonte: elaborado pelos autores.

\subsubsection{Sugestões de melhoria}

Sempre que houver avaria nas embalagens, na hora da descarga, o Centro de Distribuição deve fazer um check list e imediatamente solicitar ao fabricante do produto embalagens novas sem custo para que possam ser encaminhadas para as filiais, as embalagens avariadas devem ser vendidas com os demais papelões acumulados.

Para os produtos que apresentarem muitas avarias é necessário que seja solicitado ao fabricante que venha até o Centro de Distribuição fazer uma avaliação e posteriormente um possível reforço na embalagem. 


\subsection{Armazenagem}

Entre todos os itens analisados a armazenagem foi a que mais se aproximou do nível desejado de desempenho próximo dos $75 \%$.

Gráfico 7 - Armazenagem

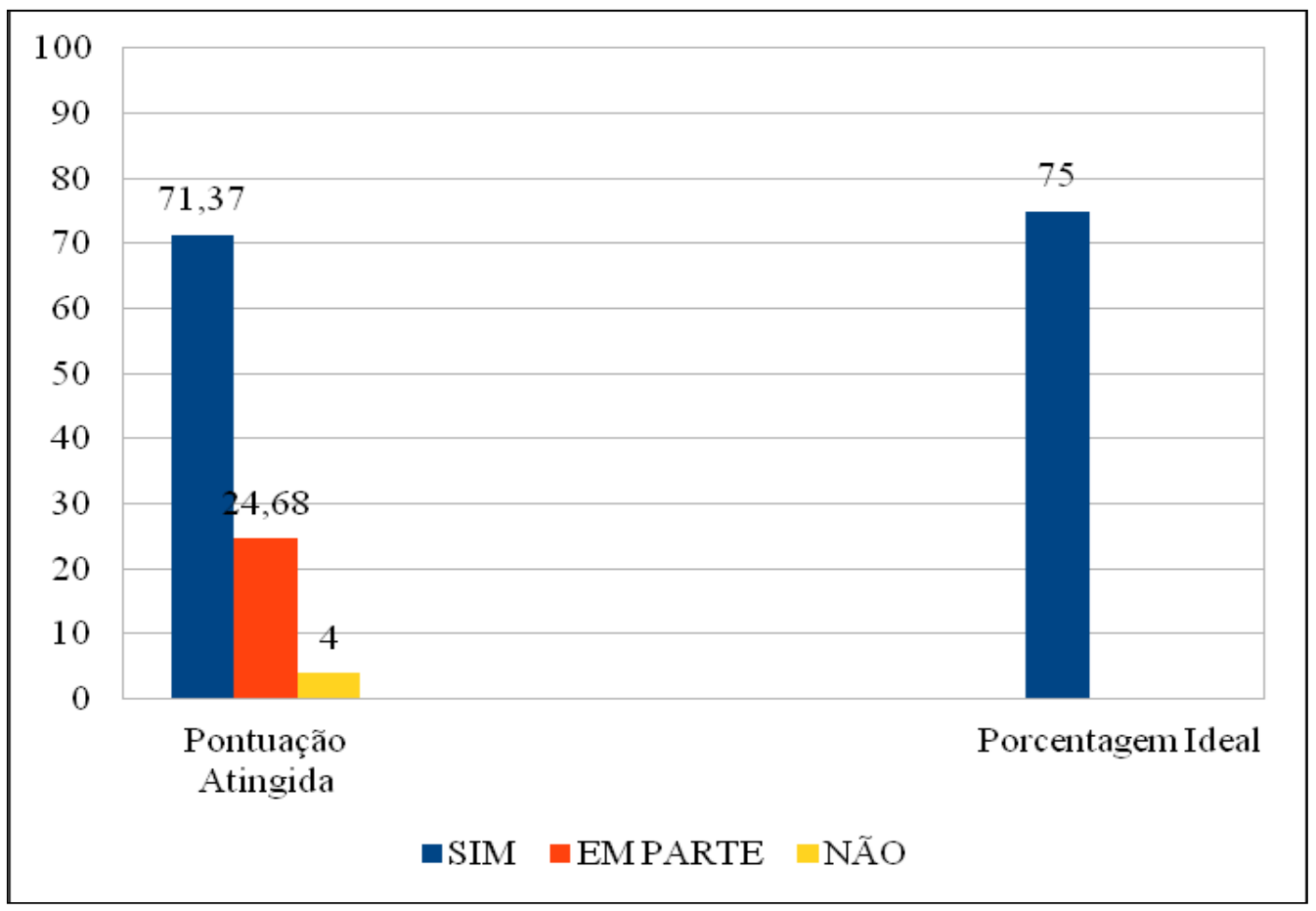

Fonte: elaborado pelos autores.

\subsubsection{Sugestões de melhoria}

Para os produtos com muito estoque e pouca venda que ficam por muito tempo armazenados, sugere-se que sejam enviados para as lojas com preços promocionais, para que sua data da validade junto ao fabricante não seja ultrapassada.

Sugere-se a Direção da empresa junto ao Setor de Segurança do Trabalho que sejam feitos treinamentos com os operadores de empilhadeiras e paleteiras para serem orientados sobre como devem conduzir seus equipamentos, armazenando os produtos com segurança e da melhor forma possível.

Para um bom armazenamento e ambiente organizado é necessário a limpeza dos corredores diariamente bem como das prateleiras que os produtos serão armazenados. 
Para manter os estoques sempre atualizados e com uma boa acuracidade foi sugerido fazer auditorias internas por família de produtos, onde o tempo de contagem é menor e não atrapalha o andamento dos demais setores.

\subsection{Expedição}

A avaliação da expedição foi boa com mais de $68 \%$ as respostas foram positivas, é um setor que é preciso planejamento e organização para fluir com eficiência.

Gráfico 8 - Expedição

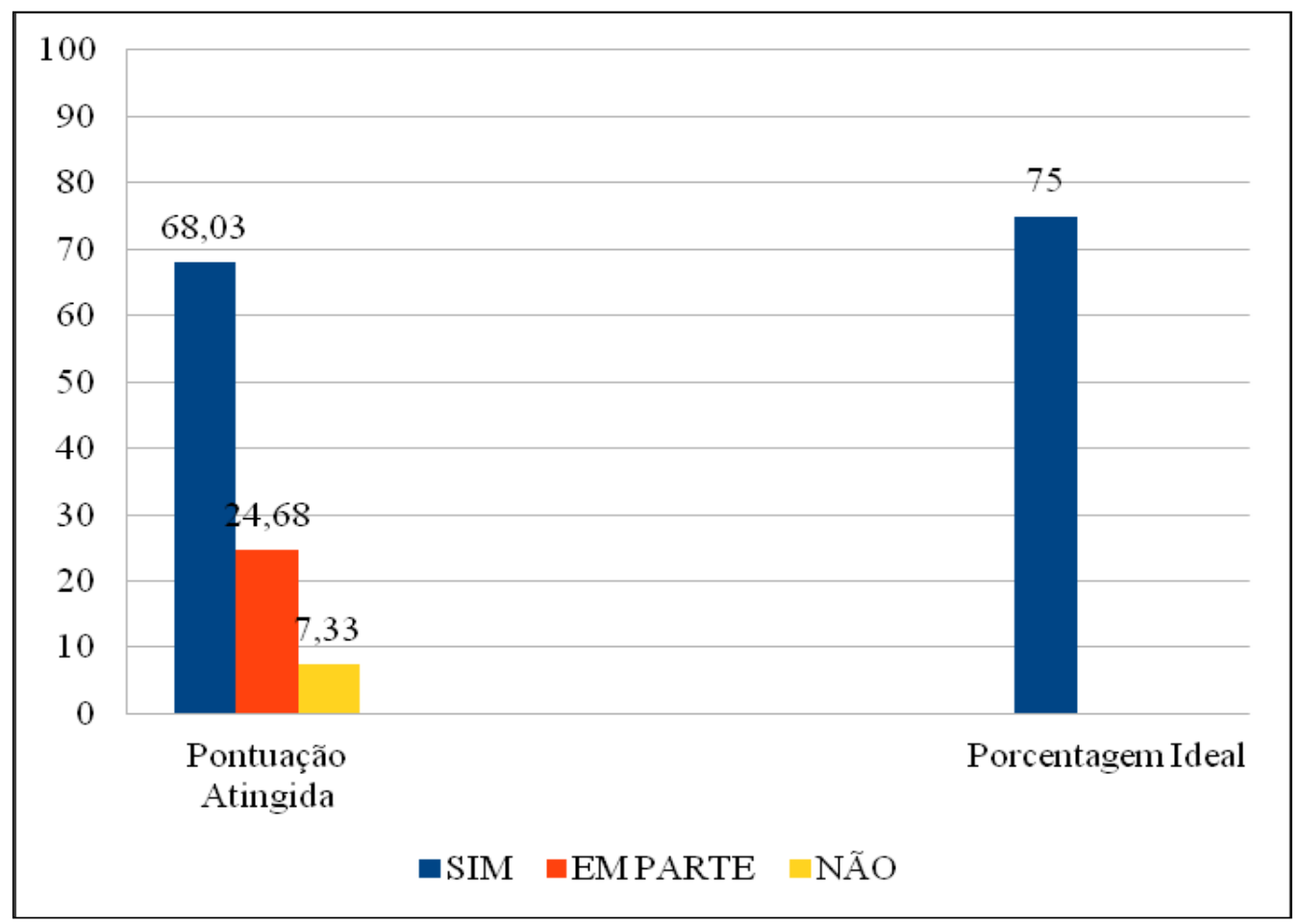

Fonte: elaborado pelos autores.

\subsubsection{Sugestões de melhoria}

Para evitar que falte determinado produto solicitado pela loja sugerese que a conferência seja feita por duas pessoas diferentes, a primeira faz a conferência do item manualmente e a segunda com o coletor antes de entrar o produto no caminhão. Sugere-se elaborar um check list para ser utilizado antes do carregamento, por exemplo, com alguns dados do produto, dados da embalagem (vistoria manual das condições), produtos frágeis ser informado em qual parte do caminhão vai ser carregado. 


\section{CONSIDERAÇÕES FINAIS}

As redes varejistas estão a cada ano mais competitivas e cada vez mais tem forçado as empresas a buscarem melhores resultados, diferenciais e um serviço de excelência aos seus clientes. O setor de logística vem sendo muito valorizado nessa busca constante de aperfeiçoamento, antes era apenas uma área de operações, hoje é uma área estratégica da empresa, onde tem grande impacto no custo operacional.

Durante a pesquisa os funcionários que responderam aos questionários, o Coordenador de Logística que respondeu a entrevista, a Gerente do CD que colaborou para o andamento da pesquisa e demais colaboradores foram muito receptivos e solícitos, se posicionando de forma a contribuir com informações importantes para a elaboração da análise, esse processo envolveu várias pessoas de todos os setores do Centro de Distribuição.

Com relação ao objetivo apresentado nesse trabalho onde era sugerir ações de melhoria nos processos de logística interna, eles foram atingidos, pois várias oportunidades de mudança foram apontadas, onde podem trazer benefícios e melhores resultados para a empresa.

As melhorias devem ser constantes pois nenhuma empresa é imutável, todas as falhas, sugestões, críticas e análises devem vir para contribuir com o aprimoramento e um serviço com mais qualidade. A empresa deve estar atenta ao que o seu cliente diz, principalmente se ele reclamar, pois essa é uma grande oportunidade de melhorar seu serviço e desempenho.

\section{REFERÊNCIAS}

APPOLINÁRIO, Fábio. Metodologia da ciência: filolosofia e prática de pesquisa. São Paulo: Pioneira Thomson Learning, 2006.

BALLOU, Ronald H. Gerenciamento da cadeia de suprimentos/logística empresarial. Porto Alegre: Bookman, 2006.

BANZATO, Eduardo; FONSECA, Luiz R. P. da. Projetos de Armazéns. São Paulo: IMAM, 2008.

BEUREN, Ilse M. Como elaborar trabalhos de monografia em Contabilidade: teoria e prática. 3. ed. São Paulo, 2006.

CAMPOS, Luiz F. R. Supply Chain: uma visão gerencial. Curitiba: Intersaberes, 2012.

CHEMIN, Beatris F. Manual da Univates para trabalhos acadêmicos: planejamento, elaboração e apresentação. 3. ed. Lajeado: ed. Univates, 2015.

CHOPRA, Sunil.; MEINDL, Peter. Gerenciamento da cadeia de suprimentos. São Paulo: Prentice Hall, 2003. 
FIGUEIREDO, Antônio M. de; SOUZA, GOUDINHO, Soraia R. Como elaborar projetos, monografias, dissertações e teses: da redação científica à apresentação do texto final. 4. ed. Rio de Janeiro: Lumen Juris, 2011.

FIGUEIREDO, Kleber F.; FLEURY, Paulo F.; WANKE, Peter. Logística e gerencimento da cadeia de suprimentos: planejamento do fluxo de produtos e dos recursos. São Paulo: Atlas, 2003.

FLEURY, Paulo F.; WANKE, Peter.; FIGUEIREDO, Kleber F. Logística empresarial. São Paulo: Atlas, 2000.

GAITHER, Norman.; FRAZIER, Greg. Administração da produção e operações.

Tradução de José Carlos Barbosa dos Santos. 8. ed. São Paulo: Pioneira Thomson, 2002.

GIL, Antonio C. Métodos e técnicas de pesquisa social. 6. ed. São Paulo: Atlas, 2012.

KAMINSKY, Philip.; SIMCHI-LEVI, David.; SIMCHI-LEVI, Edith. Cadeia de suprimentos projeto e gestão: conceitos, estratégias e estudos de caso. Porto Alegre: Bookman, 2010.

MALHOTRA, Naresh K. Pesquisa de marketing: uma orientação aplicada. 4. ed. Porto Alegre: Bookman, 2006.

MARANHÃO, Mauriti.; MACIEIRA, Maria Elisa B. O Processo Nosso de Cada Dia: modelagem de processos de Trabalho. 1 ed. Rio de Janeiro: Qualitymark, 2004.

MAXIMIANO, Antonio C. A. Teoria geral da Administração: da revolução urbana a revolução digital. 7. ed. São Paulo: Atlas, 2012.

MOURA, Reinaldo A. Armazenagem: Do recebimento a expedição em almoxarifados ou centros de distribuição. São Paulo: IMAM,1997.

MOURA, Reinaldo A. Check sua logística interna. São Paulo: IMAM, 1998.

MOURA, Reinaldo A. Sistemas e técnicas de movimentação e Armazenagem de Materias. 5. ed. rev. São Paulo: Instituto IMAM, 2005. v. 1

REZENDE, Antonio C.; GASNIER, Daniel G.; CARILLO, Edson Jr.; BANZATO, Eduardo.; MOURA, Reinaldo A. Atualidades na Logística. Volume 3. São Paulo: IMAM, 2005.

RODRIGUES, Paulo R. A. Gestão estratégica da armazenagem. São Paulo: Aduaneiras, 2003.

RUSSO, Clovis P. Armazenagem, controle e distribuição. Curitiba: Ed. Ibpex, 2009. 
SORDI, José O. de. Gestão por processos: uma abordagem da moderna administração. 3. ed. São Paulo: Saraiva, 2012.

SOUSA. Paulo T. de. Logística Interna: modelo de reposição semi-automático de materiais e suprimentos - um estudo de caso no Sesc. 2002. 104 f. Dissertação (Mestrado) - Programa de Pós - Graduação em Engenharia de Produção, Universidade Federal de Santa Catarina, Florianópolis, 2002.

TAYLOR, Frederick W. Princípios de administração científica. São Paulo: Atlas, 1992. 